\section{1}

2

3

\title{
Strong transgenerational effects but no genetic adaptation in zooplankton 24 years after an abrupt $+10^{\circ} \mathrm{C}$ climate change
}

\author{
Antónia Juliana Pais-Costa ${ }^{1,2}$, Eva J. P. Lievens ${ }^{1,3^{*}}$, Stella Redón ${ }^{1,4^{*}}$, Marta I. Sánchez ${ }^{4,5}$, \\ Roula Jabbour-Zahab ${ }^{1}$, Pauline Joncour ${ }^{6}$, Nguyen Van $\mathrm{Hoa}^{7}$, Gilbert Van Stappen ${ }^{8}$, \\ Thomas Lenormand ${ }^{1 \S}$ \\ 1 CEFE, CNRS, Univ Montpellier, Univ Paul Valéry Montpellier 3, EPHE, IRD, Montpellier, France \\ 2 Marine and Environmental Sciences Centre (MARE), Faculty of Sciences and Technology, University of \\ Coimbra, Portugal \\ 3 Aquatic Ecology and Evolution, Department of Biology, University of Konstanz, 78464, Konstanz, Germany \\ 4 Department of Wetland Ecology, Estación Biológica de Doñana-CSIC, Seville, Spain \\ 5 Departamento de Biología Vegetal y Ecología, Facultad de Biología, Universidad de Sevilla, Spain \\ 6 CNRS, université Rennes 1, ECOBIO (écosystème, biodiversité, évolution) - UMR 6553 \\ 7 Department of Coastal Aquaculture, College of Aquaculture and Fisheries, Cantho University, Vietnam. \\ 8 Laboratory of Aquaculture \& Artemia Reference Center, Ghent University, B-9000 Gent, Belgium \\ $\S$ Corresponding author: thomas.lenormand@cefe.cnrs.fr \\ * equal contribution
}

Keywords: additive genetic effect, microbiota, transgenerational epigenetic effects, plasticity, climate change, missing heritability, thermal tolerance, resurrection ecology

Competing interest: The authors declare no competing interest

\section{Contact information}

juliana.pais.costa@gmail.com, eva.j.lievens@gmail.com (ORCID iD 0000-0003-3280-0072),

stellarc.bio@gmail.com (ORCID iD 0000-0001-9351-6601), marta.sanchez@ebd.csic.es,

roula.zahab@cefe.cnrs.fr, pauline.joncour@univ-rennes1.fr, nvhoa@ctu.edu.vn,

Gilbert.VanStappen@UGent.be, thomas.lenormand@cefe.cnrs.fr (ORCID iD 0000-0001-8930-5393)

Data sharing plan: data and codes will be made available on Dryad upon acceptance

Author contribution:

Conceptualization TL, MS; Experiments, AJPC, SR, RJZ, EJPL; Formal Analysis, EJPL, TL, PJ; Sampling NVH, GVS, RJZ, TL; Writing-Original Draft, AJPC, TL, EJPL; Writing-revision, all.; Supervision and funding, TL, MS. 
63 Understanding how biodiversity responds to global warming, and anticipating whether species will

\section{Abstract}

The climate is currently warming fast, threatening biodiversity all over the globe. Adaptation is often rapid when the environment changes quickly, but for climate warming very little evidence is available. Here, we investigate the pattern of adaptation to an extreme $+10^{\circ} \mathrm{C}$ climate change in the wild, following the introduction of brine shrimp Artemia franciscana from San Francisco Bay, USA, to Vinh Chau saltern in Vietnam. We use a resurrection ecology approach, hatching diapause eggs from the ancestral population and the introduced population after 13 and 24 years (resp. $~ 54$ and $~ 100$ generations). In a series of coordinated experiments, we determined whether the introduced Artemia show increased tolerance to higher temperatures, and the extent to which genetic adaptation, developmental plasticity, transgenerational effects, and local microbiome differences contributed to this tolerance. We find that introduced brine shrimp do show increased phenotypic tolerance to warming. Yet strikingly, these changes do not have an additive genetic component, are not caused by mitochondrial genetic variation, and are not caused by epigenetic marks set by adult parents exposed to warming. Further, we do not find any developmental plasticity in response to warming, nor any protective effect of heat-tolerant local microbiota. We conclude that the evolution of shrimp's extreme thermal tolerance is only due to transgenerational (great)grandparental effects, possibly epigenetic marks set by parents who were exposed to high temperatures as juveniles. This finding challenges standard models of genetic and plastic adaptive responses, and our conception of how species may cope with climate warming.

\section{Significance statement}

Adaptation is often rapid when environments change quickly, but for climate warming little evidence is available. Many studies report no genetic responses due to pre-existing plasticity, while others point towards epigenetics and microbiota effects. In this study, we take advantage of a natural experiment to study all of these effects. We use a set of coordinated experiments and a 'resurrection ecology' approach, reviving resting eggs of brine shrimp up to100 generations after their introduction from a temperate to a tropical saltern. We find that heat adaptation occurs, but heritability is fully "missing". Plasticity and microbiota play no role either, indicating that only transgenerational (great)grandmaternal effects are involved. This finding prompts us to reconsider the relative importance of the different possible mechanisms by which phenotypic change can occur, especially in response to temperature variation. 
scientific challenges (Hoffmann and Sgrò, 2011). While rapid genetic adaptation to novel humanmade environmental changes - polution, pesticides, antibiotics - has been extensively documented (Hendry et al., 2017), much less has been observed for climate warming (Franks and Hoffmann, 2012; Gienapp et al., 2008; Hoffmann and Sgrò, 2011; Merilä and Hendry, 2014; Stoks et al., 2014). This discrepancy might be due to the (yet) modest climate change or to the fact that many pre-existing mechanisms are already in place in most species to cope with the current range of climatic variation.

Theoretically, several mechanisms may cause a phenotypic response to climate warming (Franks and Hoffmann, 2012; Gienapp et al., 2008). First, organisms may genetically evolve to better tolerate high temperatures, and this process may extend their tolerance outside their current thermal niche. They may also phenotypically adjust to these changes using pre-existing plastic responses, within (Chevin and Hoffmann, 2017; Lande, 2015) or across generations (maternal effects, transgenerational epigenetic effects (Auge et al., 2017; Lind and Spagopoulou, 2018)). Finally they may also benefit from symbionts / microbiota adapted to these new conditions (Frankel-Bricker et al., 2020; Nougué et al., 2015; Vannier et al., 2015), without adapting to these conditions themselves. These sources of variation are mutually non-exclusive and can interact in ways that are difficult to disentangle (for instance maternal effects may be mediated by transmitted symbionts, epigenetic marks, or maternal plastic responses (Palumbi et al., 2014; Schlichting and Wund, 2014; Vannier et al., 2015)).

\section{Results}

We investigated whether species can adapt in the wild beyond their climatic niche, with the aim of disentangling these different effects. We used a resurrection ecology approach to assess the thermal adaptive potential of natural populations of the brine shrimp Artemia franciscana over 24 years (ca. 100 generations) following an abrupt climatic shift (Lenormand et al., 2018). In the early 1980s, A. franciscana from San Francisco Bay, USA (hereafter SFB) were introduced into Vinh Chau salterns, Vietnam (hereafter $\mathrm{VCH}$ ), where mean (air) temperatures are $+10^{\circ} \mathrm{C}$ higher (Clegg et al., 2000; Frankenberg et al., 2000). This far exceeds the worst IPCC climate warming scenario for the 21st century (RCP8.5 Model predicts $+6^{\circ} \mathrm{C}$ (IPCC, 2013)), yet the brine shrimp have thrived (Van Hoa, 2014), and show phenotypic adaptation to high temperatures (Clegg et al., 2000; Kappas et al., 2004). Indeed, VCH Artemia are now commonly used to inoculate other (sub)tropical salterns. We used a series of coordinated experiments to determine the extent to which the introduced Artemia's phenotypic adaptation to higher temperatures resulted from genetic changes, pre-existing plastic responses, transgenerational effects or the effect of locally adapted microbiota (Fig. S1 presents expectations). 
We compared the temperature tolerance of an ancestral population from SFB (cysts collected in 1984; hereafter $\mathrm{SFB}_{84}$ ) with that of two populations from VCH (cysts collected in 1997 and 2008; hereafter $\mathrm{VCH}_{97}$ and $\left.\mathrm{VCH}_{08}\right)$. We resurrected an $\mathrm{F} 0$ generation from each population and kept them at a standardized lab temperature, thus removing plastic maternal effects. We then measured juvenile survival in the F1 generation in common garden experiments under temperatures mimicking daily thermal conditions in SFB and $\mathrm{VCH}$ (hereafter $\mathrm{T}_{\mathrm{SFB}}$ and $\mathrm{T}_{\mathrm{VCH}}$ ). This experiment was repeated several times as the 'control' treatment in the juvenile acclimation, parental acclimation, and microbiota experiments (see below). Very consistently in these controls, $\mathrm{VCH}$ populations raised in the laboratory showed increased juvenile survival compared to the original $\mathrm{SFB}_{84}$ population, but only when exposed to a $\mathrm{VCH}$ climate (meta-analysis $\chi^{2}(1)=9.6, p=0.002$ at $\mathrm{T}_{\mathrm{VCH}}$ and $\chi^{2}(1)=0.8, p=0.38$ at $\mathrm{T}_{\mathrm{SFB}}$; Fig. 1A solid points). The $\mathrm{VCH}$ populations are thus phenotypically adapted to high temperatures, consistent with previous studies (Clegg et al., 2000; Frankenberg et al., 2000; Kappas et al., 2004), and this is not due to direct plastic maternal effects since all F0 females were raised in

112 the same conditions or to different resource allocation of $\mathrm{VCH}$ females to their offspring as the effect

113 is specific to $\mathrm{VCH}$ temperature. Furthermore, $\mathrm{VCH}_{08}$ juveniles had significantly higher survival at $114 \mathrm{~T}_{\mathrm{VCH}}$ than $\mathrm{VCH}_{97}$ juveniles (post-hoc $z=3.1, p=0.002$; Fig. 1A), so phenotypic adaptation increased 115 over time in $\mathrm{VCH}$.

A second, crucial, step was to determine whether this increased performance resulted from genetic changes. If so, $\mathrm{VCH}_{97}$ and $\mathrm{VCH}_{08}$ males should be able to transmit at least part of this increased performance to their progeny when crossed with reference SFB females from a stock cultured for over two years under standardized experimental conditions (see methods). This cross removed any maternal and (great)-grandmaternal effects that might have contributed to the observed 121 phenotypic variation. Assuming that adaptation to warmer climate is a polygenic trait, we expect 122 roughly half of the additive genetic effects to be transmitted through males. We would therefore 123 expect to see increased performance at $\mathrm{T}_{\mathrm{VCH}}$ for the crossed $\mathrm{VCH}_{97}$ and $\mathrm{VCH}_{08}$ populations but not 124 for the crossed $\mathrm{SFB}_{84}$ population in the same juvenile survival test. Despite the strong phenotypic 125 change observed in the uncrossed F1s, survival was not significantly different in juveniles from 126 crossed $\mathrm{SFB}_{84}, \mathrm{VCH}_{97}$ and $\mathrm{VCH}_{08}$ populations in either temperature treatment ( $p=0.44$ for a 127 population-level difference at $\mathrm{T}_{\mathrm{SFB}} ; p=0.16$ at $\mathrm{T}_{\mathrm{VCH}}$; Table $\mathrm{S} 2$, Fig. $1 \mathrm{~A}$ open points). This means that 128 the increased performance of $\mathrm{VCH}$ Artemia at $\mathrm{T}_{\mathrm{VCH}}$ did not result from additive genetic effects. 129 Instead, it may have resulted from (i) fully recessive genetic effects, (ii) maternal genetic effect, 130 notably through mitochondrial evolution, or (iii) plastic grandmaternal (or earlier great131 grandmaternal, etc.) effects, e.g. the transmission of epigenetic marks acquired in VCH. Although not 132 formally excluded, the recessivity hypothesis is unlikely as thermal adaptation likely involves 
133

134

135

136

137

138

139

140

141

142

143

144

145

146

147

148

149

150

151

152

153

154

155

156

157

158

159

160

161

162

163

164

165

numerous quantitative traits with at least some additive effects, and as recessive beneficial alleles (here conferring thermal tolerance) are not expected to sweep quickly in a large population as would be required to explain the rapid phenotypic change observed here (Fig. S3). We investigated the possibility of mitochondrial evolution by sequencing the mitochondrial genome of 10 individuals from $\mathrm{SFB}_{84}$ and $\mathrm{VCH}_{08}$, as well as sequencing pooled cysts from $\mathrm{VCH}$ collected at eight dates between 1984 and 2008. SNP analyses show that mitotype frequencies were remarkably stable over that period, excluding a role for adaptation via the mitochondrial genome (Fig. 2, methods). Hence, it is most likely that the $\mathrm{VCH}$ populations have not adapted genetically to higher temperatures. This finding is surprising, but other studies on adaptation to climate warming have also reported an absence of genetic response (Franks et al., 2014; Gienapp et al., 2008; Merilä and Hendry, 2014). Frankenberg et al. (Frankenberg et al., 2000) also showed that VCH Artemia populations (hatched from field cysts collected in 1994) had increased survival at high temperature (compared to SFB cysts collected in 1978), but this increased performance was not apparent in later laboratory generations. Such a finding could result from transgenerational effects, supporting our third hypothesis of plastic (great)grandmaternal effects. Grandmaternal effects are also supported by the study of Norouzitallab et al. (Norouzitallab et al., 2014), who report transgenerational epigenetic effects on thermal tolerance in laboratory A. parthenogenetica, which were transmitted up to the $\mathrm{F} 3$ generations.

To further investigate these transgenerational effects, we tested whether thermal exposure of adult parents to $\mathrm{T}_{\mathrm{VCH}}$ could influence progeny performance at $\mathrm{T}_{\mathrm{SFB}} \mathrm{vs} \mathrm{T}_{\mathrm{VCH}}$. If so, we would have a mechanism for the grandparental effects (provided they could be maintained for one more generation). We compared juvenile survival in clutches produced before and after exposing their parents to high temperatures ("Parental acclimation" experiment). We exposed the mother, the father, or neither parent. Comparing within the same family controlled for biases resulting from differential mortality of parents exposed to the different treatments; comparisons with families where neither parent was exposed controlled for a second clutch effect. Results showed no significant differences in survival between clutches from the different parental treatments at $\mathrm{T}_{\mathrm{SFB}}$ or $\mathrm{T}_{\mathrm{VCH}}$ for any Artemia population $\left(0.08 \leq p \leq 0.36\right.$ for a population, parental treatment, or interaction effect at $\mathrm{T}_{\mathrm{SFB}}$; $0.15 \leq p \leq 0.41$ at $\mathrm{T}_{\mathrm{VCH}}$; Table S2, Fig. 1B), indicating that thermal exposure in the parent does not influence the thermal tolerance of its progeny. This experiment rules out that epigenetic marks are set in adults in the time window preceding clutch production. However, it does not exclude epigenetic marks that are set during the juvenile development of the parents (or grandparents, etc.) (Donelson et al., 2018; Norouzitallab et al., 2014). The imprint may be set early during meiosis in the female germ line, which occurs during juvenile development (Lenormand et al., 2016). Indeed, the epigenetic 
166 effects referenced above were found after exposing juvenile A. parthenogenetica to a heat shock 167 (Norouzitallab et al., 2014).

168 Next, we investigated whether Artemia have a developmental plasticity response to the thermal environment. Such a plastic response would not be sufficient to explain the phenotypic effects that we observed, since these experiments did not include an acclimation phase before measurement.

171 However, if plastic adjustment to cope with high temperatures pre-existed in SFB, or evolved in VCH, 172 this would help explain the lack of genetic change in $\mathrm{VCH}$. This possibility is reinforced by previous 173 studies in Artemia, which demonstrated plastic response to thermal stress (Clegg et al., 2000; 174 Frankenberg et al., 2000). To investigate this possibility, we exposed 5-day-old juveniles to $\mathrm{T}_{\mathrm{SFB}}$ or $175 \mathrm{~T}_{\mathrm{VCH}}$ for 2 days, and then tested whether pre-exposure increased performance in each environment 176 ("Juvenile acclimation" experiment) during the same age window used for the other experiments. 177 Strikingly, we found that early exposure to $\mathrm{T}_{\mathrm{VCH}}$ did not increase juvenile survival at $\mathrm{T}_{\mathrm{VCH}}$ in any of 178 the Artemia populations ( $p \geq 0.62$ for an effect of pre-exposure or its interaction with population; Table 179 S2, Fig. 1C). In contrast, pre-exposure to $\mathrm{T}_{\mathrm{VCH}}$ significantly increased survival at $\mathrm{T}_{\mathrm{SFB}}(p<0.0001$ for a pre-exposure effect; Table S2, Fig. 1C) for all three Artemia populations ( $p=0.31$ for an interaction with population; Table S2), indicating that there is indeed a plastic response (e.g. activation of heat shock proteins (Clegg et al., 2000; Frankenberg et al., 2000)). However, this plasticity does not confer improved performance at $\mathrm{T}_{\mathrm{VCH}}$, so we can rule out that it plays a role in the thermal adaptation at $\mathrm{VCH}$.

Last, we investigated whether performance at $\mathrm{T}_{\mathrm{SFB}}$ and $\mathrm{T}_{\mathrm{VCH}}$ could be affected by the presence of microbiota adapted to those climates ("Microbiota" experiment). In corals, for example, the temperature niche is controlled by that of their symbionts (Littman et al., 2010). Artemia host many gut bacteria that are essential for the proper digestion of unicellular algae, their main food source. Adaptation of this microbiota to high salinity has been shown to determine their host's salinity niche (Nougué et al., 2015). Hence, it is possible that Artemia's thermal niche is controlled in part by the thermal niche of its microbiome. Such a finding would also help explain the lack of genetic change in $\mathrm{VCH}$. To evaluate this possibility, we investigated the thermal tolerance of axenic Artemia from $\mathrm{SFB}_{84}, \mathrm{VCH}_{97}$, and $\mathrm{VCH}_{08}$ populations inoculated with microbes sampled from live Artemia in SFB, $\mathrm{VCH}$, or our reference laboratory cultures. If microbes contribute to thermal tolerance, we would expect $\mathrm{VCH}$ microbes to increase juvenile survival at $\mathrm{T}_{\mathrm{VCH}}$, but not $\mathrm{T}_{\mathrm{SFB}}$, whereas $\mathrm{SFB}$ microbes 197 that having microbes from $\mathrm{VCH}$ increased survival for all Artemia populations at both $\mathrm{T}_{\mathrm{SFB}}$ and $\mathrm{T}_{\mathrm{VCH}}$, 198 while having lab microbes decreased survival in all circumstances $(p=0.003$ for an interaction 199 between population and microbiome at $\mathrm{T}_{\mathrm{SFB}} ; p=0.001$ at $\mathrm{T}_{\mathrm{VCH}}$; Table S2, Fig. 1D). Hosting VCH 
microbes appears to simply be better than hosting lab microbes. For the SFB microbes, we found that they conferred the same survival as $\mathrm{VCH}$ microbes in $\mathrm{SFB}_{84}$ but were equally poor as the lab microbes for both $\mathrm{VCH}$ populations. Hence, our results are consistent with the idea that (i) microbes have a large impact on survival, (ii) microbes from our three stocks are different and (iii) their effect depends on the Artemia population. We did not find any indication that the microbes play a role in thermal adaptation. Interestingly, we found that Artemia had no problems when exposed to microbiota from a tropical climate: they are available, and there is no need to specifically adapt to them (as $\mathrm{SFB}_{84}$ performed equally well with VCH microbes). All our findings are consistent with a loss of function in the laboratory microbes, and by a loss of ability of the Vietnamese Artemia to cope with their ancestral SFB microbes.

\section{Discussion}

In summary, we found no indication of genetic adaptation to increased temperature in a field situation which should a priori be very favourable for the evolution of thermal tolerance (Reznick and Ghalambor, 2001): a large and isolated sexual population without initial bottleneck, exposed to a large and abrupt environmental shift over 100 generations. However, we did find a phenotypic difference when testing individuals whose grandmothers were exposed to high temperatures, and this difference was larger for the $\mathrm{VCH}_{08}$ population than for $\mathrm{VCH}_{97}$. We conclude that $\mathrm{VCH}$ Artemia have higher heat tolerance due to transgenerational effects, and that these effects increased through time, e.g. by being better maintained through generations in more recent Vietnamese populations. Such effects are not entirely unexpected, as they are found more often in short-lived, dispersal-limited organisms, for juvenile traits, and in conditions where environmental variation is predictable over several generations (Yin et al., 2019). Further work is necessary to see whether these transgenerational effects are due to epigenetic marks, as in (Norouzitallab et al., 2014), or due to other mechanisms. Their presence could explain the lack of genetic changes in $\mathrm{VCH}$ : transgenerational effects could keep the population phenotype close to a thermal optimum, thereby reducing directional selection and genetic changes. Such interference with genetic adaptation has been found in many studies reporting within-generation plasticity (Gienapp et al., 2008; Merilä and Hendry, 2014), but the transgenerational mechanism found here is much less documented. Transgenerational effects may be difficult to detect: though the resurrection ecology approach is among the most powerful methods to study adaptation to climate change (Lenormand et al., 2018; Nogués-Bravo et al., 2018; Orsini et al., 2013; Weider et al., 2018), without crosses we would have concluded that genetic adaptation had taken place (as in Geerts et al., 2015; Yousey et al., 2018). Compared to other studies, our adaptive transgenerational effects are large (Jeremias et al., 2018; Sánchez-Tójar et al., 2020; Yin et al., 2019), and contrast strikingly with the absence of adaptive genetic and within-generation plastic effects, 
234 providing an example where adaptation involves traits whose heritability is entirely "missing"

235 (Trerotola et al., 2015). Overall, this work represents one of the most complete studies jointly

236 addressing the different factors associated with thermal adaptation in the wild, namely genetic effects,

237 epigenetic effects, plasticity, and microbiota. It shows that phenotypic adaptation to an extreme

238 environmental change can be achieved by transgenerational effects and suggests that these effects can

239 be so large that no genetic adaptation takes place.

240

241

242

243

244

245

246

247

248

249

250

251

252

253

254

255

256

257

258

259

260

261

262

263

264

265

266

267

\section{Acknowledgments}

We thank N. Rode, G. Martin, L.-M. Chevin, and A. Charmantier for contributing to a pilot experiment; Y. Michalakis, C. Teplitsky, S. Glémin, L.-M. Chevin and N. Bonel for suggestions and comments on the manuscript; C. Mahieu for maintaining the ARC cyst collection; and Susan de La Cruz and David Nelson from San Francisco Bay Estuary Field Station for providing live SFB Artemia for the microbiota experiment. We thank M.-P. Dubois and The Genomics, Molecular Ecology, and Experimental Evolution platform (GEMEX) at CEFE; the genotyping and sequencing facilities of the Institut des Sciences de l'Evolution (GENSEQ); the Labex Centre Méditerranéen de l'Environnement et de la Biodiversité (CEMEB); and the MGX sequencing platform in Montpellier. Financial support was provided by MUSE Kim Sea and Coast, CNRS and Fundación BBVA (Ref 201632009) and FCT Portugal, through MARE (UID/MAR/04292/2013), and through the PhD grant of A. J. Pais-Costa (SFRH/BD/108224/2015).

\section{References}

Auge GA, Leverett LD, Edwards BR, Donohue K. 2017. Adjusting phenotypes via within- and across-generational plasticity. New Phytol 216:343-349. doi:10.1111/nph.14495

Bates D, Maechler M, Bolker B, Walker S. 2015. Fitting Linear Mixed-Effects Models Using lme4. J Stat Softw 67:1-48. doi:10.18637/jss.v067.i01

Chevin LM, Hoffmann AA. 2017. Evolution of phenotypic plasticity in extreme environments. Philos Trans R Soc B Biol Sci 372:20160138. doi:10.1098/rstb.2016.0138

Clegg JS, Jackson SA, Hoa N V, Sorgeloos P. 2000. Thermal resistance, developmental rate and heat shock proteins in Artemia franciscana, from San Francisco Bay and southern Vietnam. $J$ Exp Mar Bio Ecol 252:85-96.

Crow JF, Kimura M. 1970. An Introduction to Population Genetics Theory. Caldwell, NJ, USA: The Blackburn Press. doi:10.2307/1529706

Donelson JM, Salinas S, Munday PL, Shama LNS. 2018. Transgenerational plasticity and climate change experiments: Where do we go from here? Glob Chang Biol 24:13-34. doi:10.1111/gcb.13903

Frankel-Bricker J, Song MJ, Benner MJ, Schaack S. 2020. Variation in the microbiota associated 
with Daphnia magna across genotypes, populations, and temperature. Microb Ecol 79:731742. doi:10.1007/s00248-019-01412-9

Frankenberg MM, Jackson SA, Clegg JS. 2000. The heat shock response of adult Artemia franciscana. J Therm Biol 25:481-490.

Franks SJ, Hoffmann AA. 2012. Genetics of Climate Change Adaptation. Annu Rev Genet 46:185208. doi:10.1146/annurev-genet-110711-155511

Franks SJ, Weber JJ, Aitken SN. 2014. Evolutionary and plastic responses to climate change in terrestrial plant populations. Evol Appl 7:123-139. doi:10.1111/eva.12112

Geerts AN, Vanoverbeke J, Vanschoenwinkel B, Van Doorslaer W, Feuchtmayr H, Atkinson D, Moss B, Davidson TA, Sayer CD, De Meester L. 2015. Rapid evolution of thermal tolerance in the water flea Daphnia. Nat Clim Chang 5:665-668. doi:10.1038/nclimate2628

Gienapp P, Teplitsky C, Alho JS, Mills JA, Merilä J. 2008. Climate change and evolution: disentangling environmental and genetic responses. Mol Ecol 17:167-178. doi:10.1111/j.1365-294X.2007.03413.x

Harrison XA. 2015. A comparison of observation-level random effect and Beta-Binomial models for modelling overdispersion in Binomial data in ecology \& evolution. PeerJ 3:e1114. doi:10.7717/peerj.1114

Hendry AP, Gotanda KM, Svensson EI. 2017. Human influences on evolution, and the ecological and societal consequences. Philos Trans R Soc Lond B Biol Sci 372:20160028. doi:10.1098/rstb.2016.0028

Hoffmann AA, Sgrò CM. 2011. Climate change and evolutionary adaptation. Nature 470:479-485. doi:10.1038/nature09670

IPCC. 2013. Summary for policymakersClimate Change 2014: Impacts, Adaptation, and Vulnerability. Part A: Global and Sectoral Aspects. Contribution of Working Group II to the Fifth Assessment Report of the Intergovernmental Panel on Climate Change.

Jeremias G, Barbosa J, Marques SM, Asselman J, Gonçalves FJM, Pereira JL. 2018. Synthesizing the role of epigenetics in the response and adaptation of species to climate change in freshwater ecosystems. Mol Ecol 27:2790-2806. doi:10.1111/mec.14727

Kappas I, Abatzopoulos TJ, Van Hoa N, Sorgeloos P, Beardmore JA. 2004. Genetic and reproductive differentiation of Artemia franciscana in a new environment. Mar Biol 146:103117. doi:10.1007/s00227-004-1420-9

Lande R. 2015. Evolution of phenotypic plasticity in colonizing species. Mol Ecol 24:2038-2045. doi:10.1111/mec.13037

Lenormand T, Bourguet D, Guillemaud T, Raymond M. 1999. Tracking the evolution of insecticide 
resistance in the mosquito Culex pipiens. Nature 400:861-864. doi:10.1038/23685

Lenormand T, Engelstädter J, Johnston SESE, Wijnker E, Haag CR. 2016. Evolutionary mysteries in meiosis. Philos Trans R Soc B-Biological Sci 371:20160001. doi:10.1101/050831

Lenormand T, Nougué O, Jabbour-Zahab R, Arnaud F, Dezileau L, Chevin L-M, Sánchez MI. 2018. Resurrection ecology in Artemia. Evol Appl 11:76-87. doi:10.1111/eva.12522

Lind MI, Spagopoulou F. 2018. Evolutionary consequences of epigenetic inheritance. Heredity. doi:10.1038/s41437-018-0113-y

Littman RA, Bourne DG, Willis BL. 2010. Responses of coral-associated bacterial communities to heat stress differ with Symbiodinium type on the same coral host. Mol Ecol 19:1978-1990. doi:10.1111/j.1365-294X.2010.04620.x

Martin G, Lambert A. 2015. A simple, semi-deterministic approximation to the distribution of selective sweeps in large populations. Theor Popul Biol 101:40-46. doi:10.1016/J.TPB.2015.01.004

Merilä J, Hendry AP. 2014. Climate change, adaptation, and phenotypic plasticity: The problem and the evidence. Evol Appl 7:1-14. doi:10.1111/eva.12137

Nogués-Bravo D, Rodríguez-Sánchez F, Orsini L, de Boer E, Jansson R, Morlon H, Fordham DA, Jackson ST. 2018. Cracking the Code of Biodiversity Responses to Past Climate Change. Trends Ecol Evol 33:765-776. doi:10.1016/j.tree.2018.07.005

Norouzitallab P, Baruah K, Vandegehuchte M, Van Stappen G, Catania F, Vanden Bussche J, Vanhaecke L, Sorgeloos P, Bossier P. 2014. Environmental heat stress induces epigenetic transgenerational inheritance of robustness in parthenogenetic Artemia model. FASEB J. doi:10.1096/fj.14-252049

Nougué O, Gallet R, Chevin L-ML-M, Lenormand T. 2015. Niche limits of symbiotic gut microbiota constrain the salinity tolerance of brine shrimp. Am Nat 186:390-403. doi:10.5061/dryad.366nd

Orsini L, Schwenk K, De Meester L, Colbourne JK, Pfrender ME, Weider LJ. 2013. The evolutionary time machine: Using dormant propagules to forecast how populations can adapt to changing environments. Trends Ecol Evol 28:274-282. doi:10.1016/j.tree.2013.01.009

Palumbi SR, Barshis DJ, Traylor-Knowles N, Bay RA. 2014. Mechanisms of reef coral resistance to future climate change. Science 344:895-898. doi:10.1126/science.1251336

R Core Team. 2014. R: A language and environment for statistical computing.

Reznick DN, Ghalambor CK. 2001. The population ecology of contemporary adaptations: What empirical studies reveal about the conditions that promote adaptive evolution. Genetica 112113:183-198. doi:10.1023/A:1013352109042 
Sánchez-Tójar A, Lagisz M, Moran NP, Nakagawa S, Noble DWA, Reinhold K. 2020. The jury is still out regarding the generality of adaptive 'transgenerational' effects. Ecol Lett 23:17151718. doi:10.1111/ele.13479

Schlichting CD, Wund MA. 2014. Phenotypic plasticity and epigenetic marking: An assessment of evidence for genetic accommodation. Evolution 68:656-672. doi:10.1111/evo.12348

Stoks R, Geerts AN, De Meester L. 2014. Evolutionary and plastic responses of freshwater invertebrates to climate change: Realized patterns and future potential. Evol Appl 7:42-55. doi:10.1111/eva.12108

Trerotola M, Relli V, Simeone P, Alberti S. 2015. Epigenetic inheritance and the missing heritability. Hum Genomics. doi:10.1186/s40246-015-0041-3

Van Hoa N. 2014. Artemia production in southern Vietnam: geographical, soil structure, climatic and culture technique updating. Int J Artemia Biol 4:30-37.

Vannier N, Mony C, Bittebière A-K, Vandenkoornhuyse P. 2015. Epigenetic Mechanisms and Microbiota as a Toolbox for Plant Phenotypic Adjustment to Environment. Front Plant Sci 6:1159. doi:10.3389/fpls.2015.01159

Viechtbauer W. 2010. Conducting meta-analyses in R with the metafor package. J Stat Softw 36:148.

Weider LJ, Jeyasingh PD, Frisch D. 2018. Evolutionary aspects of resurrection ecology: Progress, scope, and applications-An overview. Evol Appl 11:3-10. doi:10.1111/eva.12563

Yin J, Zhou M, Lin Z, Li QQ, Zhang YY. 2019. Transgenerational effects benefit offspring across diverse environments: a meta-analysis in plants and animals. Ecol Lett 22:1976-1986. doi:10.1111/ele.13373

Yousey AM, Chowdhury PR, Biddinger N, Shaw JH, Jeyasingh PD, Weider LJ. 2018. Resurrected 'ancient' Daphnia genotypes show reduced thermal stress tolerance compared to modern descendants. R Soc Open Sci 5:172193. doi:10.1098/rsos.172193 
A. Additive effects

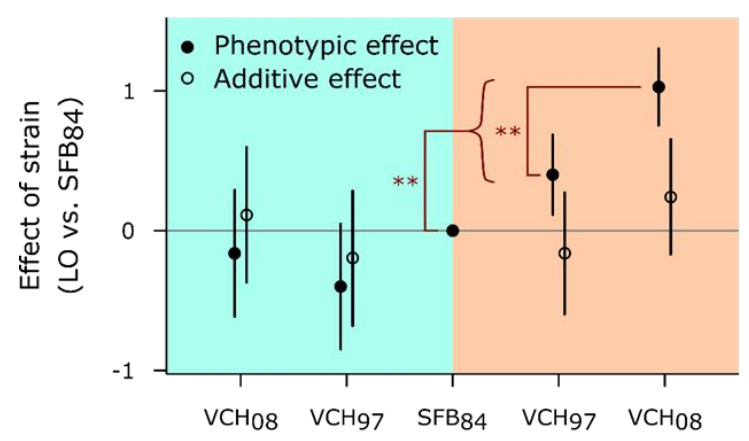

C. Juvenile acclimation

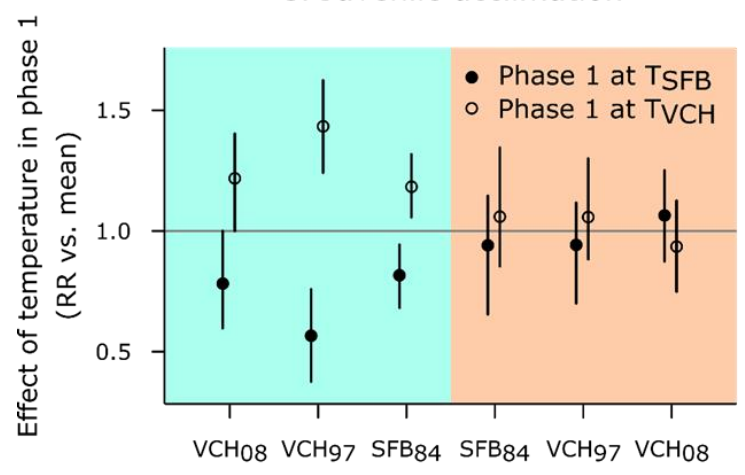

Artemia population

362

363

364

365

366

367

368

369

370

371

372

373

374

375

376

377
B. Parental acclimation

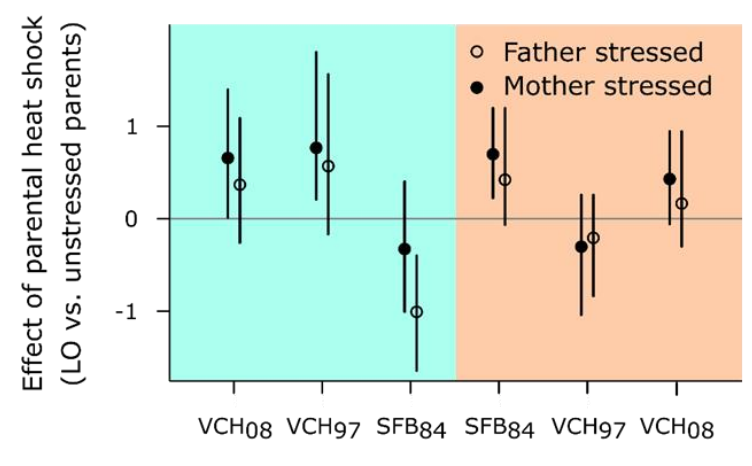

D. Microbiome

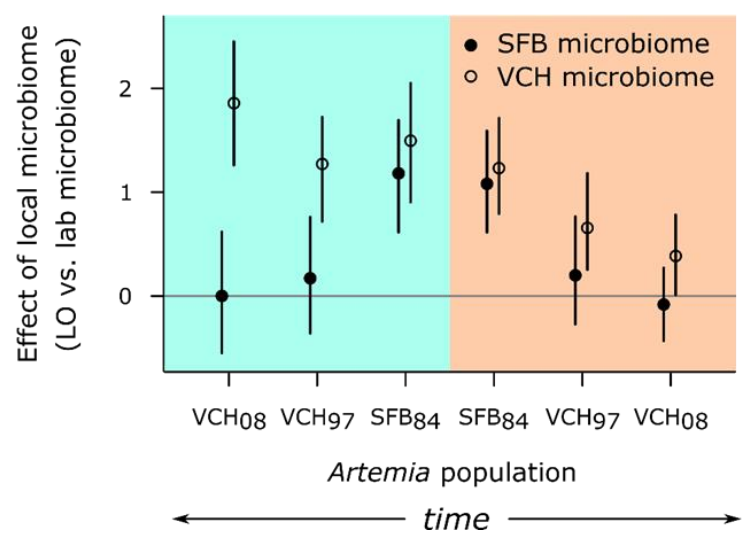

Figure 1. Disentangling the effects of genetics, parental acclimation, juvenile acclimation, and microbiome on phenotypic adaptation to high temperatures. Blue and orange backgrounds represent assays run at $\mathrm{T}_{\mathrm{SFB}}$ and $\mathrm{T}_{\mathrm{VCH}}$, respectively. The grey line corresponds to a lack of effect; bars are CIs. To maintain clarity, only significant differences relevant to the phenotypic adaptation to high temperature in VCH are shown; for other $p$-values see Supp. Table 2. Abbreviations: LO, log odds ratio of survival; RR, relative risk of survival. A) Survival of the VCH strains compared to the ancestral $\mathrm{SFB}_{84}$, when mothers belonged to the own population (solid points) and to an SFB reference population ('crossed' populations, empty points). The '0' point for $\mathrm{SFB}_{84}$ is included for reference. B) Difference in survival between the second and first clutches, when parents were exposed to high temperature between clutches 1 and 2. The effect of the second clutch itself (which may have differed in survival compared to the first) is controlled for using the second vs. first clutch effect observed for the unexposed control parents. C) Survival in Phase 2, after exposure to $\mathrm{T}_{\mathrm{SFB}}$ or $\mathrm{T}_{\mathrm{VCH}}$ in Phase 1. Here, 'mean' is the mean survival in Phase 2 for each strain. D) Survival after inoculation with a local microbiome, compared to survival with the reference lab microbiome. 


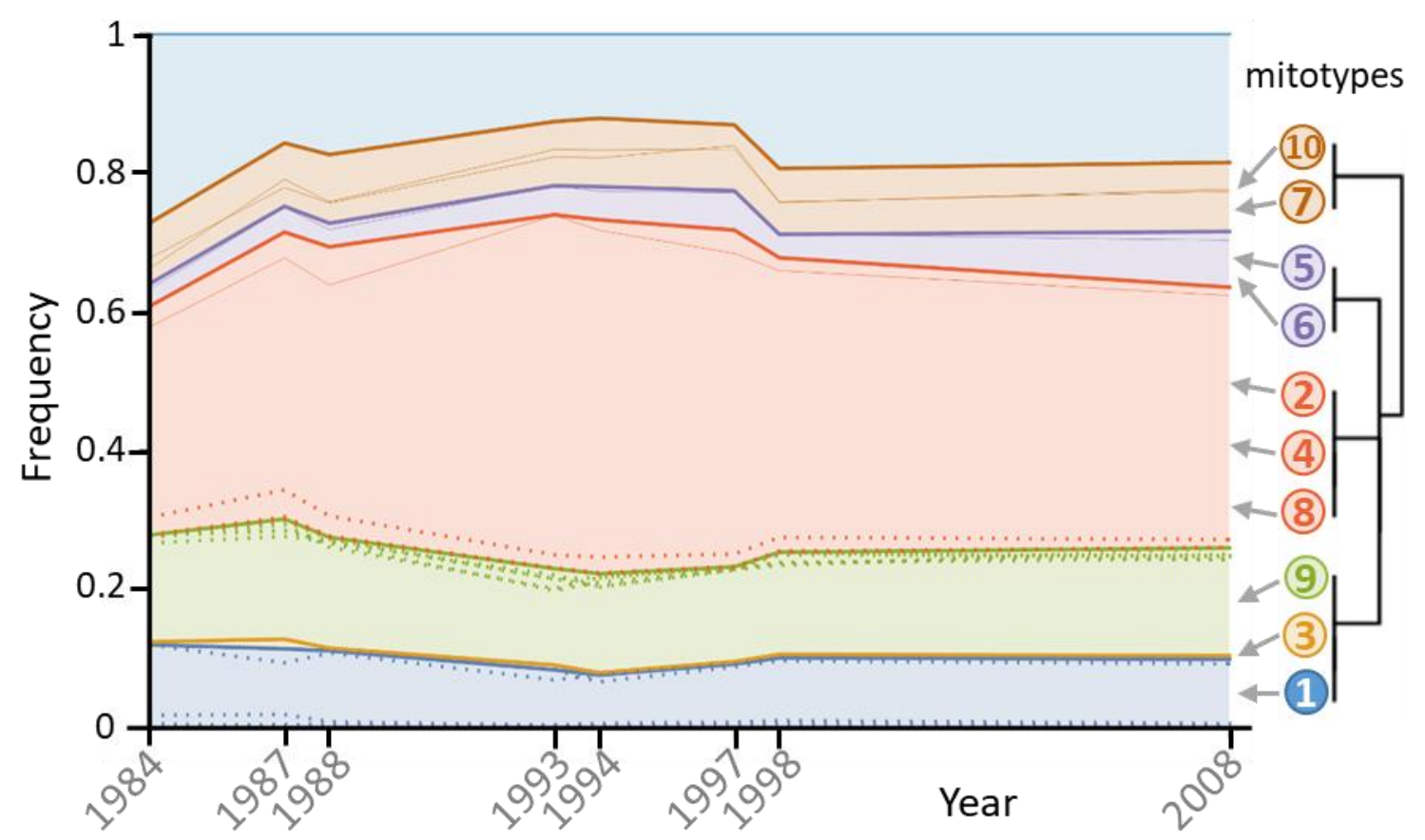

379 Figure 2. Mitotype frequency variation through time. Sampled years are shown on the $x$-axis, the $y$ 380 axis expresses cumulative frequency. The relationship between the different mitotypes (based on 381 shared-SNP, methods) is shown by the dendrogram on the right. Mitotypes are shown with different 382 colors; numbers identify the individual sequenced (1-5 from 1984 and 6-10 from 2008). The 383 mitotypes' frequency envelope is that of their most frequent shared-SNP. Individuals 1, 3, and 9 do 384 not have shared-SNPs, and are therefore grouped on this dendrogram. Their frequency envelope is 385 that of their most frequent private-SNP. Thin lines represent other shared-SNP frequencies within 386 mitotypes. Dotted lines represent private-SNPs within groups (only those reaching a frequency $>1 \%$ 387 are shown). 
390

391

392

393

394

395

396

397

398

399

400

401

402

403

404

405

406

407

408

409

410

411

412

413

414

415

416

417

418

419

420

\section{Methods}

Experiments were performed with three populations of A. franciscana: one from San Francisco Bay (SFB), USA, collected in 1984 ( $\left.\mathrm{SFB}_{84}\right)$; a second from Vinh Chau (VCH) saltern, Vietnam, collected in $1997\left(\mathrm{VCH}_{97}\right)$; and a third, also from $\mathrm{VCH}$, collected in $2008\left(\mathrm{VCH}_{08}\right)$.

\section{Decapsulation and hatching of the cysts:}

The parental generation of experimental individuals (see below) was hatched from dormant cysts. Cyst decapsulation and hatching protocols were modified from Bengtson et al. (1991). Cysts were rehydrated in deionized water ( $2 \mathrm{~h}$ to $3 \mathrm{~h}$ ). After rehydration, cysts were decapsulated by a $10 \mathrm{~min}$ exposure to a sodium hypochlorite solution, then rinsed with running water (10 min) and deionized water $(5 \mathrm{~min})$. Decapsulated cysts were incubated for $48 \mathrm{~h}$ at $28{ }^{\circ} \mathrm{C}\left( \pm 1^{\circ} \mathrm{C}\right)$, with constant light and aeration, in a $5 \mathrm{~g} / \mathrm{L}$ salinity medium (see below). After emergence, first-instar nauplii were moved to $23{ }^{\circ} \mathrm{C}\left( \pm 1^{\circ} \mathrm{C}\right)$ and natural light conditions. Salinity was gradually increased to $80-90 \mathrm{~g} / \mathrm{L}$ over 8-9 days. This procedure was performed independently for the three different Artemia populations.

\section{Baseline experimental conditions}

Throughout the preparation and execution of the experiments, Artemia were kept in a 80-90 g/L saline medium prepared by diluting field-collected concentrated brine (280 g/L, Camargue Pêche, France) from Aigues-Mortes saltern with deionized water. Organisms were fed a solution of Tetraselmis chuii algae (Fitoplankton marino, Spain), prepared by dissolving $1 \mathrm{~g}$ of lyophilized algae in $1 \mathrm{~L}$ of deionized water (c.a. $6.8 \times 10^{9}$ T. chuii cells/L). Stock individuals were fed ad libitum. Food was added daily (1 $1 \mathrm{ml}$ of algae /per group of juveniles / day; and $1 \mathrm{ml}$ of algae / per couple / day) before exposure and 3 times a week ( $2 \mathrm{ml}$ of algae / group of juveniles / 2 days) during exposure to the temperature treatments. Unless specifically mentioned, individuals were kept at $23{ }^{\circ} \mathrm{C}\left( \pm 1{ }^{\circ} \mathrm{C}\right)$, under natural light conditions. Juvenile survival tests were all performed in the dark in incubators and thermostatic chambers. Mortality was checked twice (5 and 10 days after the beginning of the treatment, i.e. midway through and at the end of the thermal treatment).

\section{SFB and VCH temperature regimes}

The same temperature regimes were applied in each experiment. Two temperature cycles were used: i) cycle of temperatures based on the air temperatures from $\mathrm{SFB}\left(\mathrm{T}_{\mathrm{SFB}}\right): 16^{\circ} \mathrm{C}(2 \mathrm{~h}) ; 22{ }^{\circ} \mathrm{C}(8 \mathrm{~h}) ; 27$ ${ }^{\circ} \mathrm{C}(4 \mathrm{~h}) ; 22{ }^{\circ} \mathrm{C}(8 \mathrm{~h}) ; 16^{\circ} \mathrm{C}(2 \mathrm{~h})$; and ii) cycle of temperatures based on the air temperatures from VCH saltern $\left(\mathrm{T}_{\mathrm{VCH}}\right): 26{ }^{\circ} \mathrm{C}(2 \mathrm{~h}) ; 32{ }^{\circ} \mathrm{C}(8 \mathrm{~h}) ; 37{ }^{\circ} \mathrm{C}(4 \mathrm{~h})$ for experiment 2 and $35^{\circ} \mathrm{C}(4 \mathrm{~h})$ for the remaining experiments; $32{ }^{\circ} \mathrm{C}(8 \mathrm{~h}) ; 26^{\circ} \mathrm{C}(2 \mathrm{~h})$. 


\section{1}

422

423

424

425

426

427

428

429

430

431

432

433

434

435

436

437

438

439

440

441

442

443

444

445

446

447

448

449

450

451

452

453

\section{Experiment 1: microevolution/adaptation}

This experiment was performed to measure the additive genetic effect of thermal adaptation, removing maternal lineage effects. For this experiment, we collected virgin females from a laboratory population of A. franciscana from SFB, hatched from cysts collected in 2003 ( $\left.\mathrm{SFB}_{03}\right)$. The $\mathrm{SFB}_{03}$ population was maintained in the laboratory for over 2 years, so it was well acclimated to the standard laboratory temperature conditions $\left(23^{\circ} \mathrm{C} \pm 1{ }^{\circ} \mathrm{C}\right)$. For $\mathrm{SFB}_{84}, \mathrm{VCH}_{97}$, and $\mathrm{VCH}_{08}$, we hatched individuals from field cysts. Before individuals reached sexual maturity, their sex was assigned based on sexual dimorphism. After maturity, males from the three study populations of Artemia were mass crossed (animals divided into 4 replicates) with the virgin stock females $\left(\mathrm{SFB}_{03}\right)$ to produce an $\mathrm{F} 1$ generation. Starting $24 \mathrm{~h}$ after the first nauplii were seen, we collected daily batches of nauplii from the mass crosses. This ensured that the organisms used in each replicate were born within the same period. Newborn nauplii from each cross were maintained in $50 \mathrm{ml}$ Falcon tubes (max. 30 nauplii per tube) filled with $30 \mathrm{ml}$ of brine solution for a period of 7 days. After 7 days, all meta-nauplii from the same cross were mixed and then separated into replicate groups of 10 individuals. Each group was placed in a $50 \mathrm{ml}$ Falcon tube filled with $30 \mathrm{ml}$ of brine solution, and exposed to $\mathrm{T}_{\mathrm{SFB}}$ or $\mathrm{T}_{\mathrm{VCH}}$ for 10 days ( $7^{\text {th }}$ to $17^{\text {th }}$ day). 30-32 groups per population were exposed to each cycle of temperatures (1830 individuals in total).

\section{Experiment 2: Parental acclimation}

This experiment was designed to investigate the possibility that thermal exposure in the parents could influence juvenile performance at high temperature. Individuals were hatched from $\mathrm{SFB}_{84}, \mathrm{VCH}_{97}$, and $\mathrm{VCH}_{08}$ field cysts. Before they reached sexual maturity, their sex was assigned based on sexual dimorphism. After maturity, single pairs of males and females from each population were isolated in $50 \mathrm{ml}$ Falcon tubes filled with $30 \mathrm{ml}$ of brine solution to produce an $\mathrm{F} 1$ generation. We collected the first brood of nauplii produced by each parental couple. Each brood of nauplii was isolated from their parents after confirming, under a stereomicroscope, that the female ovisac was empty. In this way, we ensured that the organisms used in each replicate were born within the same period. Immediately after the first clutch $\left(\mathrm{CL}_{1}\right)$ was born, the parents were separated, and one of three treatments was applied: i) mother exposed to high temperature; ii) father exposed to high temperature; and iii) control (none exposed to high temperature). The 'high temperature' treatment consisted of $8 \mathrm{~h}$ at $35^{\circ} \mathrm{C}( \pm 1$ $\left.{ }^{\circ} \mathrm{C}\right)$ in the dark. Afterwards, the couples were put back together to produce a second clutch $\left(\mathrm{CL}_{2}\right)$, which we collected in the same way. Newborn nauplii were kept in $50 \mathrm{ml}$ Falcon tubes (max. 30 nauplii per tube) filled with $30 \mathrm{ml}$ of brine solution for a period of 7 days. After 7 days, meta-nauplii from each family were separated into groups of 10 individuals and placed in $50 \mathrm{ml}$ Falcon tubes filled 
454 with $30 \mathrm{ml}$ of brine solution. A minimum of 5 replicate groups were tested per couple. Each replicate 455 was exposed to $\mathrm{T}_{\mathrm{SFB}}$ or $\mathrm{T}_{\mathrm{VCH}}$ for 10 days ( $7^{\text {th }}$ to $17^{\text {th }}$ day). Overall, 39.3 groups (SD 9.4) were used 456 per treatment, population, and temperature regime combination (survival of 7080 individuals assayed 457 in total).

458 Experiment 3: Juvenile acclimation

459 This experiment was conducted to study if very early exposure of the organisms to a thermal regime 460 would increase their performance as juveniles under the same regime. Individuals were hatched from $461 \mathrm{SFB}_{84}, \mathrm{VCH}_{97}$, and $\mathrm{VCH}_{08}$ field cysts. Before individuals reached sexual maturity, their sex was 462 assigned based on sexual dimorphism. After maturity, single pairs of males and females from the 463 same population were placed in $50 \mathrm{ml}$ Falcon tubes filled with $30 \mathrm{ml}$ of brine solution to produce an 464 F1 generation. We collected newborn nauplii from the parental couples. Each brood was isolated after confirming, under a stereomicroscope, that the female ovisac was empty. In this way, it was ensured that the organisms used in each replicate were born within the same period. Newborn nauplii were counted and separated into $50 \mathrm{ml}$ tubes containing $30 \mathrm{ml}$ brine solution (maximum 30 nauplii per tube). Nauplii were then maintained under the same conditions of light, food and temperature as the parents for a period of 5 days. After 5 days, meta-nauplii entered the experiment, which was divided into 2 phases $\left(\mathrm{P}_{1}\right.$ and $\left.\mathrm{P}_{2}\right)$. At day 5, a first temperature regime was applied for two days $\left(\mathrm{P}_{1}\right)$. Metanauplii from each family were separated into $50 \mathrm{ml}$ Falcon tubes (max. 30 nauplii per tube) filled

472 with $30 \mathrm{ml}$ of brine solution and assigned to either $\mathrm{T}_{\mathrm{SFB}}$ or $\mathrm{T}_{\mathrm{VCH}}$. Broods were discarded whenever it 473 was impossible to obtain two replicates (one per temperature regime) with a minimum of 10 474 individuals each. After this first phase $\left(\mathrm{P}_{1}\right)$, mortality was checked, and surviving meta-nauplii were 475 separated into groups and placed into $50 \mathrm{ml}$ Falcon tubes (no more than 14 individuals per falcon) 476 filled with $30 \mathrm{ml}$ of brine solution. Broods were discarded whenever it was impossible to obtain two 477 replicates (one per temperature regime) with a minimum of 5 individuals each. Meta-nauplii from 478 each population and temperature regime were again assigned to $\mathrm{T}_{\mathrm{SFB}}$ or $\mathrm{T}_{\mathrm{VCH}}$ for the second phase $479\left(\mathrm{P}_{2}\right)$. Hence, different individuals were exposed to different temperature histories: $\mathrm{T}_{\mathrm{SFB}} \rightarrow \mathrm{T}_{\mathrm{SFB}}, \mathrm{T}_{\mathrm{SFB}}$

$480 \rightarrow \mathrm{T}_{\mathrm{VCH}}, \mathrm{T}_{\mathrm{VCH}} \rightarrow \mathrm{T}_{\mathrm{SFB}}, \mathrm{T}_{\mathrm{VCH}} \rightarrow \mathrm{T}_{\mathrm{VCH}}$. Survival during this second phase was recorded for a period of 48110 days ( $7^{\text {th }}$ to $17^{\text {th }}$ day). Overall, 48.8 (SD 12.0) groups were used per temperature history $\left(\mathrm{P}_{1} \rightarrow \mathrm{P}_{2}\right)$ 482 and population combination (survival of 5315 individuals assayed in total).

\section{Experiment 4: Microbiota}

484 This experiment was designed to investigate whether exposing organisms to microbiota adapted to different climates lent their hosts different performance in those climates. $\mathrm{SFB}_{84}, \mathrm{VCH}_{97}$, and $\mathrm{VCH}_{08}$ 486 field cysts were rehydrated in sterile deionized water ( $2 \mathrm{~h}$ to $3 \mathrm{~h})$. After rehydration, cysts were 
487

488

489

490

491

492

493

494

495

496

497

498

499

500

501

502

503

504

505

506

507

508

509

510

511

512

513

514

515

516

517

518

decapsulated by a 10 min exposure to a sodium hypochlorite solution, then rinsed with deionized water (10 $\mathrm{min}$ ) and sterile deionized water $(5 \mathrm{~min})$. Decapsulated cysts were then incubated for 3 days at $28{ }^{\circ} \mathrm{C}\left( \pm 1{ }^{\circ} \mathrm{C}\right)$ and under constant light, in sealed bottles containing $400 \mathrm{~mL}$ autoclaved brine solution $(5 \mathrm{~g} / \mathrm{L})$. After emergence, first-instar nauplii were placed at $23{ }^{\circ} \mathrm{C}\left( \pm 1{ }^{\circ} \mathrm{C}\right)$ under constant light and fed with sterilized $T$. chuii solution. This procedure was performed independently for the three different populations. Salinity was gradually increased to $80-90 \mathrm{~g} / \mathrm{L}$ over $8-9$ days. When salinity reached $40 \mathrm{~g} / \mathrm{L}$, nauplii from each population were separated into 3 groups and inoculated with i) microbiota from SFB ii) microbiota from $\mathrm{VCH}$ or iii) microbiota from containers in the laboratory. The microbiota inoculum was obtained by mixing crushed live adult individuals collected in 2017 in two sites in both Vinh Chau saltern (salinity 70 g/L and 90 g/L) and San Francisco Bay Estuary Field Station (salinity 70g/L and $130 \mathrm{~g} / \mathrm{L}$ ). These 2017 microbiota might differ from the original 1984 situation, but the thermal background did not significantly changed between 1984 and 2008 and those microbial communities should reflect this climatic difference. Each inoculation bottle was filled with $400 \mathrm{ml}$ of sterile deionized water and $100 \mathrm{ml}$ of microbiota solution. Sterilized T. chuii was added ad libitum. When individuals reached sexual maturity, 12 males and 12 females from each population and treatment were separated into new sterile containers and mass crossed to produce a F1 generation and kept under the same conditions as the stock. Newborn nauplii were checked daily. Each batch of nauplii was isolated within $24 \mathrm{~h}$ after the first nauplius was seen, to ensure that organisms used in the experiment were born within the same period. Newborn nauplii were separated into sterile $50 \mathrm{ml}$ tubes (max. 30 nauplii per tube) containing $26 \mathrm{ml}$ of sterile brine solution, $2 \mathrm{ml}$ of microbiota solution, and $2 \mathrm{ml}$ of autoclaved algae solution. Nauplii were then maintained under natural light at $23{ }^{\circ} \mathrm{C}\left( \pm 1{ }^{\circ} \mathrm{C}\right)$ for a period of 7 days. After 7 days, all meta-nauplii from the same treatment were mixed and separated into replicate groups of 10 individuals. Each group was placed in a sterile $50 \mathrm{ml}$ tube containing $26 \mathrm{ml}$ of sterile brine solution, $2 \mathrm{ml}$ of microbiota solution, and 2 $\mathrm{ml}$ of algae solution. To maintain the comparison with the other experiments, only the water was autoclaved to prepare the food solution for the rest of the experiment (i.e. not the lyophilized algae, which would have significantly altered the food source). Each replicate was exposed to $\mathrm{T}_{\mathrm{SFB}}$ or $\mathrm{T}_{\mathrm{VCH}}$ for 10 days $\left(7^{\text {th }}\right.$ to $17^{\text {th }}$ day). Overall, 87-103 groups (27-39 groups per microbiota treatment) per population were exposed to each temperature regime (5630 individuals in total). All feeding and transfers were performed under a laminar flow hood to prevent microbial contamination. During the experiment, the containers were closed to limit contamination, but not sealed to allow gas and oxygen exchange. 


\section{Statistical analyses}

We first analysed the overall temperature tolerance of the VCH populations compared to the ancestral $\mathrm{SFB}_{84}$. To maximize our power to detect differences between populations, we pooled the 'control' data from the acclimation and microbiome experiments. Specifically, we used: the first clutches from the 'Parental acclimation' experiment, the second clutches from the 'Parental acclimation' experiment whose parents were not exposed to high temperature; the individuals from the 'Microbiome' experiment who were inoculated with the lab microbiome; and the organisms from the 'Juvenile acclimation' experiment who had undergone the same temperature regime in Phases 1 and 2. There are of course some small differences between these experiments (i.e. the 'Juvenile acclimation' organisms had undergone a slightly longer exposure to the temperature regimes, the 'Microbiome' organisms were cultured differently), but the meta-analysis approach accounts for this additional variation. We used a multilevel meta-analysis model (R Core Team, 2014; Viechtbauer, 2010), and meta-analysed the two temperature regimes separately. Survival relative to the $\mathrm{SFB}_{84}$ population was taken as the response variable because it is the ancestral population. Effect sizes were obtained by fitting binomial models like those described below to the control data for each experiment, and extracting the log odds ratio of each $\mathrm{VCH}$ population relative to $\mathrm{SFB}_{84}$ (more details in Suppl. Table 1). Standard errors extracted from the same models were used to weight the metaanalysis. The full meta-analysis model contained $\mathrm{VCH}$ population $\left(\mathrm{VCH}_{97}\right.$ or $\left.\mathrm{VCH}_{08}\right)$ as a fixed effect, and Experiment as a random effect controlling for non-independence within experiments. The significance of $V C H$ population was then tested using likelihood ratio tests. Where relevant, post-hoc Tukey tests were performed to compare the two populations.

To analyse the individual experiments, we used generalized linear mixed models (Bates et al., 2015; R Core Team, 2014), with the number of surviving vs. dead Artemia in each replicate as the response variable (binomial response with logit link). The two temperature regimes were analysed separately (i.e. the following was repeated for $\mathrm{T}_{\mathrm{SFB}}$ and $\mathrm{T}_{\mathrm{VCH}}$ ). First, we constructed a full model that included all the experimentally manipulated factors and their interactions. The 'Additive genetic effects' models included only Population. The 'Parental acclimation' models included Population, Clutch (a dummy variable, with the first clutch coded as ' 0 ' and the second clutch as ' 1 '), and their interaction, and the interactions between these and the factor Parental treatment. By using the dummy variable and restricting Parental treatment to the interaction terms, we avoided generating spurious (and biologically impossible) estimates of the effect of Parental treatment on the first clutch. We also included a random Family term to group replicates collected from the same parental couple. In the 'Juvenile acclimation' experiment, we analysed the survival in Phase 2, which was conditional upon survival in Phase 1. The models included Population, Temperature in Phase 1, and their interaction, 
553 as well as a random Family term to group replicates collected from the same parental couple. For the

554 'Microbiome' experiment, the models included Population, Microbiome and their interaction. Where

555 necessary, the full models were corrected for overdispersion by including an observation-level

556 random effect (Harrison, 2015). Finally, the significance of the predictors was tested using likelihood

557 ratio tests. For the 'Parental acclimation' experiment, where we were only interested in the effects of

558 Population and Parental treatment on the difference between the first and second clutch, we only

559 tested the significance of the interaction terms.

560 Mitochondrial genome sequencing and analyses

561 In order to determine whether increased heat tolerance of the Vietnamese populations could be caused

562 by mitochondrial genetic variation, we sequenced the full mitochondrial genome of 10 individuals

563 (individuals 1-5 sampled in 1984, and individuals 6-10 sampled in 2008). We also sequenced pools

564 of cysts sampled in Vinh Chau saltern (25mg of cysts, ca 6500 cysts per pool) from eight years (1984,

$5651987,1988,1993,1994,1997,1998,2008)$. Three of these were replicated twice, with independent

566 DNA extraction (1984, 1997, 2008). For each sample, mitochondrial DNA was extracted using an

567 Abcam ab65321 Mitochondrial DNA isolation kit, following the manufacturer's instructions. NGS

568 libraries were constructed using a Nextera DNA flex illumina kit (ref 20018704) and sequenced (PE

569 150) on an Illumina NovaSeq 6000 (MGX platform, Montpellier).

570 For each sample, paired reads were mapped onto an A. franciscana reference sequence 571 (NC_001620.1) with bowtie2, trimming 10 bases in 5'. Read duplicates were removed with Picard

572 MarkDuplicates. Reads with a mapping quality over 20 and in proper pairs were kept with samtools

573 view. The program pysamstats was used to get the raw percentage of each base and the total coverage

574 at each position of the reference sequence. These steps were done twice, on the original reference

575 genome and on a version that was cut in the middle and had the two parts reordered. This was done

576 to avoid border effects and obtain a good mapping for the reference extremities of this circular

577 genome. A dedicated $R$ script was written to concatenate the pysamstats output files, keeping $50 \%$

578 middle positions of the two reference versions, to obtain two tables with all samples: one with the

579 percentages of alternative bases at each position and one with the coverages. SNP calling was done

580 using a dedicated Mathematica 10.1 (Wolfram) script. Genome coverage was $~ 3000 \mathrm{X}$ on average for

581 cyst pool samples (range $1000 \mathrm{X}-6000 \mathrm{X}$ ), and was $\sim 200 \mathrm{X}$ on average for individual samples (range

$58242 \mathrm{X}-336 \mathrm{X})$. Three regions showed a drop in coverage on the reference genome and were excluded

583 from further analyses (region 1: 14045-14394; region 2: 14682-14835; region 3 15409-15806).

584 Forty variable positions were identified that distinguished the 10 sampled individuals. One of them 585 was an ambiguous insertion of a variable number of T's at position 1247, and was removed. Among 
586 the 39 remaining SNPs, 7 were shared by at least two individuals and 32 were private to a single

587 individual. The shared-SNPs defined 6 non-ambiguous haplotypes (hereafter 'mitotypes'), three

588 being characterized by a combination of at least two shared-SNPs (individuals 7 and 10; individuals

5895 and 6; individuals 2, 4, and 8) and three by the absence of shared-SNPs (individuals 1, 3, and 9).

590 The frequency envelopes of the former were obtained using the frequency of their most frequent

591 shared-SNP, while the frequency envelope for the latter was based on the frequency of their most

592 frequent private-SNP (as in the absence of recombination, the sum of the frequency of private SNPs

593 cannot exceed that of shared SNPs within a mitotype).

594 The frequency of each of the 39 SNPs was estimated from the cyst pool-seq data in eight separate

595 years (Fig. 2). Frequencies at all shared and private SNPs were very highly correlated between

596 replicates $\left(R^{2}=0.995\right.$ for years $\left.1984,1997,2008\right)$, showing that the pool-seq data provided very

597 precise information (Fig. S2). Frequency data from consecutive years also showed very consistent

598 frequency estimates (Fig. 2). The cumulative frequency of the 6 mitotypes identified represented

$599 \sim 80 \%$ of the population. Other SNPs were identified in the dataset, but were not used as they could

600 not be easily clustered or assigned to a mitotype due to the lack of important temporal frequency

601 variation. Overall, the frequency pattern of the different mitotypes was remarkably stable, ruling out

602 that the genetic composition of the mitochondrial population changed significantly over the study

603 period. This therefore rules out that mitochondrial genetics explain the increased heat tolerance in the

604 Vietnamese Artemia through time.

605

606 


\begin{tabular}{llcc} 
& & \multicolumn{1}{c}{$\mathbf{T}_{\mathbf{S F B}}$} & \multicolumn{1}{c}{$\mathbf{T}_{\mathbf{V C H}}$} \\
Experiment & Fixed and random terms & Effect size $\pm \mathbf{S E}$ & Effect size $\pm \mathbf{S E}$ \\
$\begin{array}{l}\text { Parental } \\
\text { acclimation }\end{array}$ & $\sim$ VCH population $+\left(1 \mid\right.$ Family/Clutch $\left.^{2}\right)$ & $\mathrm{VCH}_{97}:-0.77 \pm 0.27$ & $\mathrm{VCH}_{97}: 0.35 \pm 0.21$ \\
$\begin{array}{l}\text { Juvenile } \\
\text { acclimation }\end{array}$ & $\sim$ VCH population $+(1 \mid$ Family/Observation $)$ & $\mathrm{VCH}_{97}: 0.38 \pm 0.68$ & $\mathrm{VCH}_{97}: 0.19 \pm 0.46$ \\
& & $\mathrm{VCH}_{08}:-0.25 \pm 0.81$ & $\mathrm{VCH}_{08}: 0.85 \pm 0.48$ \\
Microbiome & $\sim$ VCH population $+(1 \mid$ Observation $)$ & $\mathrm{VCH}_{97}:-0.18 \pm 0.28$ & $\mathrm{VCH}_{97}: 0.52 \pm 0.23$ \\
& & $\mathrm{VCH}_{08}:-0.06 \pm 0.28$ & $\mathrm{VCH}_{08}: 0.86 \pm 0.22$
\end{tabular}

607 Table S1. Models used to generate effect sizes and variances for the meta-analysis of phenotypic

608 adaptation (solid points, Fig 1A), which compared the overall temperature tolerance of VCH and SFB

609 populations. Effect sizes are the log odds ratio of survival compared to $\mathrm{SFB}_{84}$. Where necessary,

610 observation-level random effects were added to control for overdispersion. Notes: ${ }^{1}$ To estimate

611 overall survival in this experiment, we fit models for survival in Phase 1 and Phase 2, then

612 transformed, multiplied, and back-transformed the predicted survival rates. Standard errors were

613 obtained by resampling. ${ }^{2}$ These models no longer have Clutch as a fixed term, so we control for

614 possible variation in survival between the first and second clutches by including it here as a (non-

615 dummy) random effect. 


\begin{tabular}{|c|c|c|c|c|c|}
\hline \multirow[b]{2}{*}{ Experiment } & \multirow[b]{2}{*}{ Fixed-effect term } & \multicolumn{2}{|c|}{ TSFB } & \multicolumn{2}{|c|}{ Tvch } \\
\hline & & $\begin{array}{r}\text { Test } \\
\text { statistic }\end{array}$ & $P$ & Test statistic & $\boldsymbol{P}$ \\
\hline $\begin{array}{l}\text { Additive } \\
\text { genetic effects }\end{array}$ & Population & $\chi_{(2)}^{2}=1.7$ & 0.44 & $\chi^{2}(2)=3.6$ & 0.16 \\
\hline \multirow{3}{*}{$\begin{array}{l}\text { Juvenile } \\
\text { acclimation }\end{array}$} & Population & $\chi^{2}(2)=28.8$ & $<0.0001$ & $\chi_{(2)}^{2}=44.4$ & $<0.0001$ \\
\hline & Temp. in Phase 1 & $\chi^{2}(1)=30.8$ & $<0.0001$ & $\chi_{(1)}^{2}=0.0$ & 0.91 \\
\hline & Population : Temp. in Phase 1 & $\chi^{2}(2)=2.3$ & 0.31 & $\chi^{2}(2)=1.0$ & 0.62 \\
\hline \multirow{3}{*}{$\begin{array}{l}\text { Parental } \\
\text { acclimation }\end{array}$} & Clutch : Population & $\chi^{2}(2)=2.1$ & 0.36 & $\chi^{2}(2)=1.8$ & 0.41 \\
\hline & Clutch: Parental treatm. & $\chi_{(2)}^{2}=3.3$ & 0.19 & $\chi_{(2)}^{2}=3.8$ & 0.15 \\
\hline & $\begin{array}{l}\text { Clutch : Population : Parental } \\
\text { treatm. }\end{array}$ & $\chi^{2}(4)=8.3$ & 0.08 & $\chi^{2}(4)=5.6$ & 0.23 \\
\hline \multirow[t]{3}{*}{ Microbiome } & Population & - & - & - & - \\
\hline & Microbiome & - & - & - & - \\
\hline & Population : Microbiome & $\chi^{2}(4)=15.7$ & 0.003 & $\chi^{2}(4)=18.4$ & 0.001 \\
\hline
\end{tabular}

619 Table S2. Significance of the tested effects for the individual experiments. Temp., temperature; 620 treatm., treatment. 
bioRxiv preprint doi: https://doi org/10.1101/2021.02.05.429921: this version posted February 6, 2021. The copyright holder for this preprint (which was not certified by peer review) is the author/funder, who has granted bioRxiv a license to display the preprint in perpetuity. It is made available under aCC-BY-NC-ND 4.0 International license.

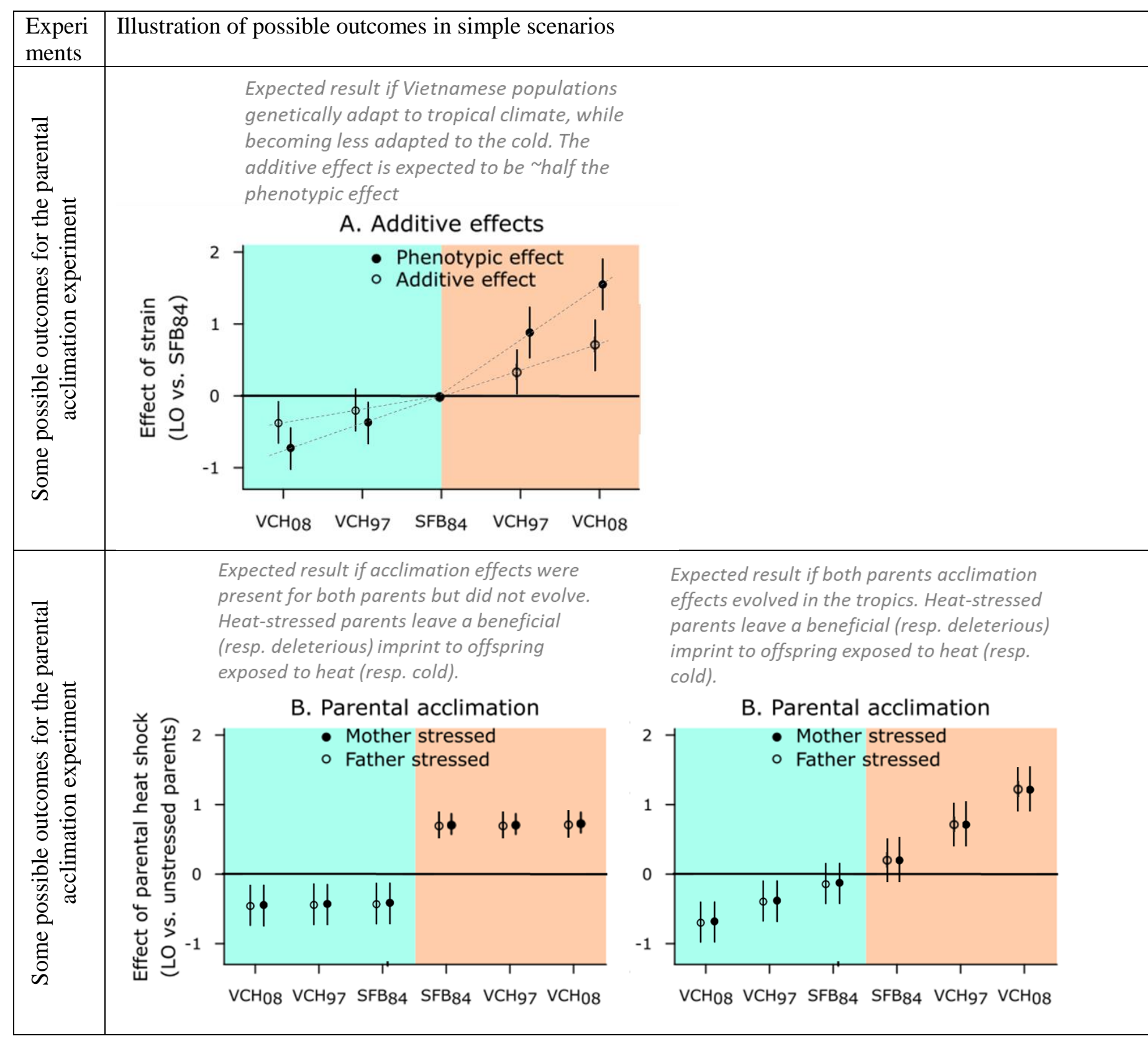


bioRxiv preprint doi: https://doi.org/10.1101/2021.02.05.429921; this version posted February 6, 2021. The copyright holder for this preprint (which was not certified by peer review) is the author/funder, who has granted bioRxiv a license to display the preprint in perpetuity. It is made available under aCC-BY-NC-ND 4.0 International license.

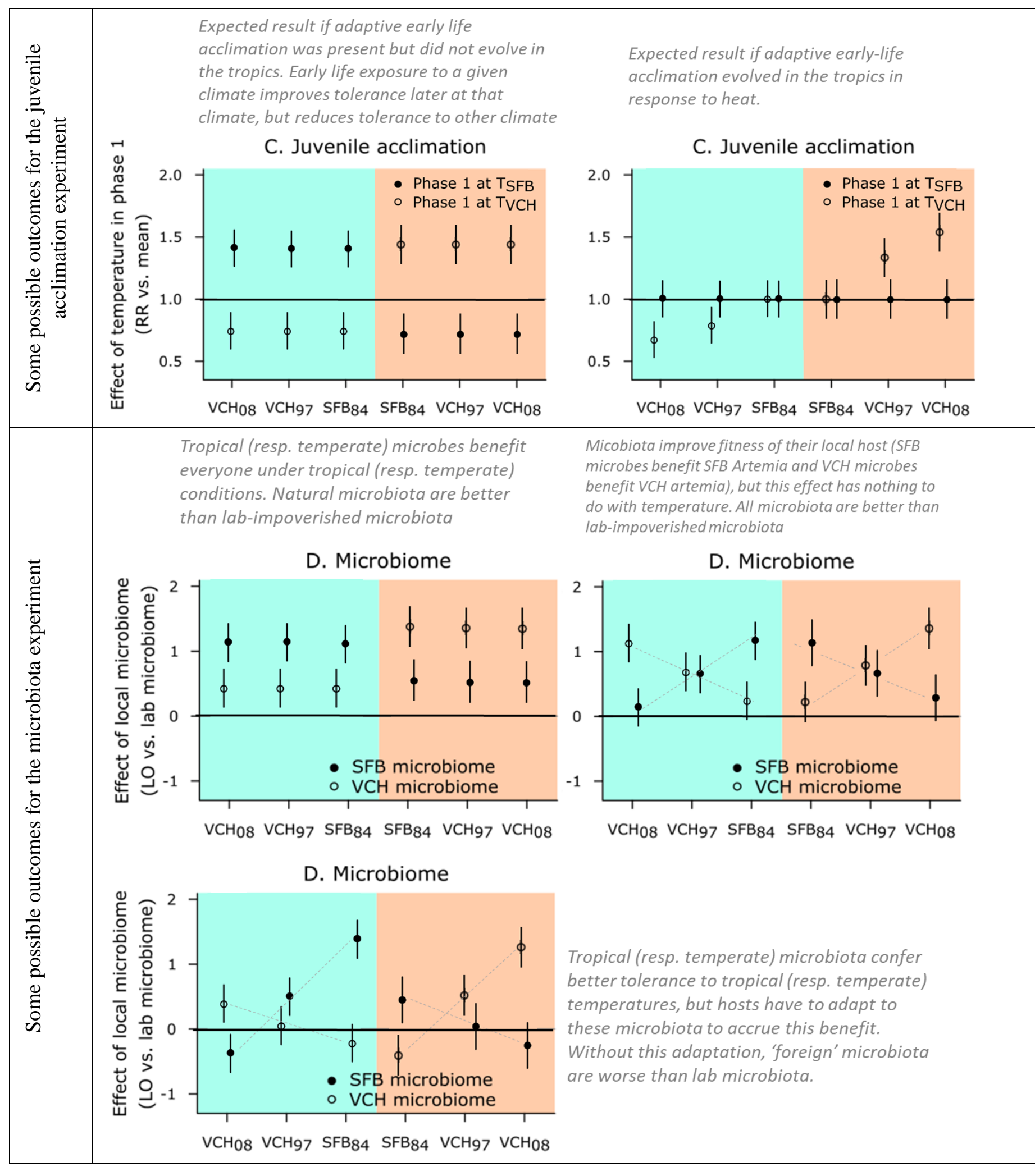

625 Figure S1. Illustration of possible outcomes for the different experiments, with simple scenarios

626 described next to the figures. 
627

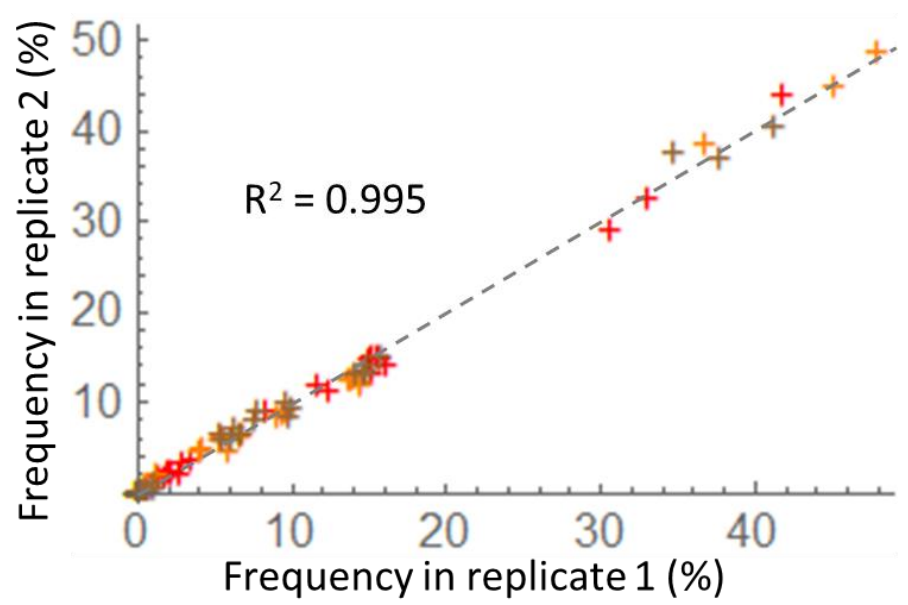

628

629 Figure S2. SNP frequency data quality. SNP frequency was independently estimated twice for years

6301984 (red), 1997 (orange), and 2008 (brown). The figure reports the correlation between these

631 replicated values for all SNPs used in Fig. 2 (all private and shared SNPs among sequenced

632 individuals). $\mathrm{R}^{2}=0.995$ over all replicated measures. Dashed line is the 1:1 line. 
634

635

636

637

638

639

640

641

642

643

644

645

646

647

648

649

650

651

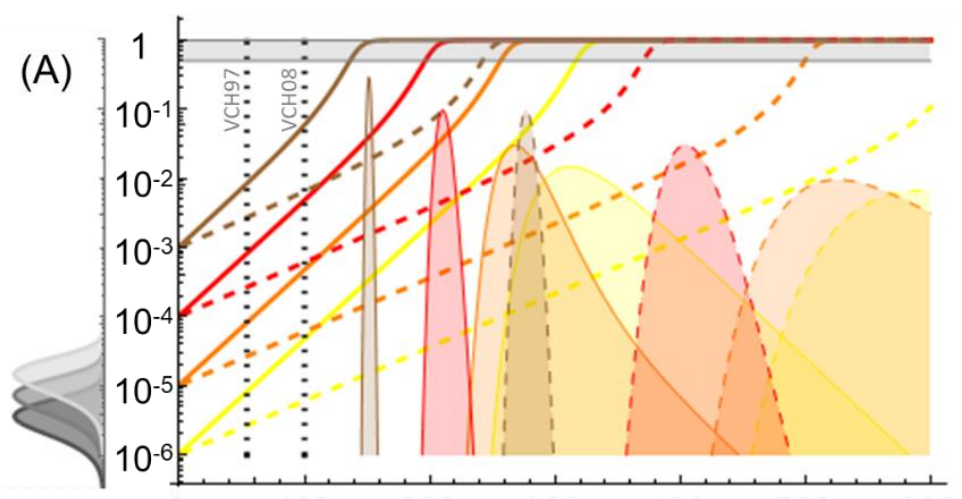

(B)

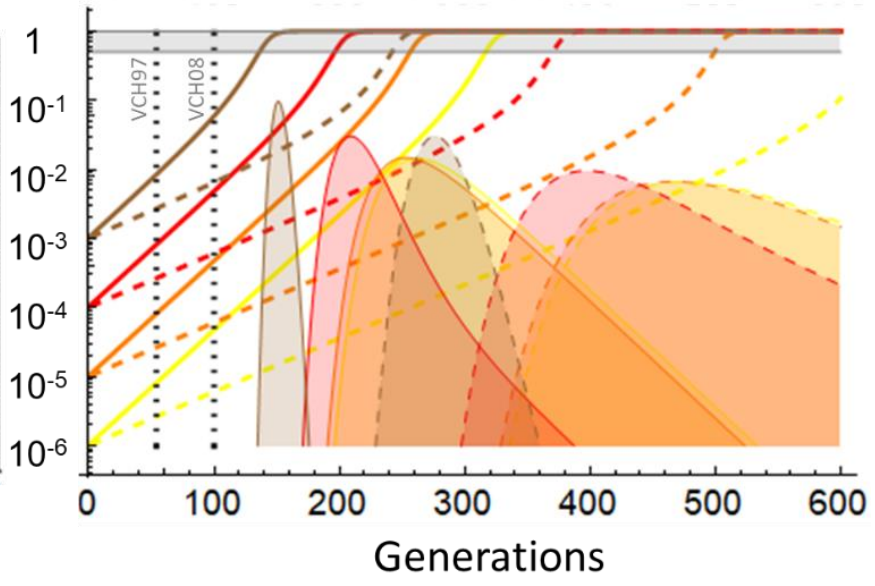

Figure S3. Frequency of a strongly beneficial recessive allele $(s=0.3)$ through time in a population of $N=10^{7}$ (panel A) or $N=10^{6}$ (panel B) individuals. Plain and dashed lines: exact deterministic frequency change for this beneficial allele given a dominance coefficient of $h=0.13$ and $h=0.06$, respectively. For these curves, the $x$-axis represents time in generations, and the $y$-axis is the frequency in log-scale. Different colors illustrate different initial frequencies, from $10^{-6}$ (yellow) to $10^{-3}$ (brown). For comparison, a newly arising mutant would start at $10^{-7}$ or $10^{-6}$ in panel A and $\mathrm{B}$, respectively. The horizontal gray bar represents the $[0.5,1]$ frequency range for the beneficial allele, within which it starts having a detectable effect on the mean fitness of the population $(\sim 10 \%$ increase in mean fitness). The vertical dotted lines correspond to our two dates of measurement (1997, at generation $\sim 54$, and 2008, at generation $\sim 100$ ). Colored surface areas show the corresponding probability density of half-sweep times (i.e. the number of generations to reach a frequency of $1 / 2$ ) from a stochastic model with $N_{e}=N$ (from Eq. 8 in (Martin and Lambert, 2015), same line and color code for dominance and initial frequency as for the deterministic curves). Here, the $x$-axis shows this half-sweep time and the $y$-axis the corresponding probability density. Distributions in grey to the left of the $y$-axis show the frequency distribution of the heat tolerance allele in its population of origin (SFB), at mutation $\left(u=10^{-7}\right)$ selection balance, assuming that it reduces fitness at cold temperatures by a modest amount ( $h s=0.02$ dark grey, 0.01 grey or 0.005 light grey) compared to its strong 
652 advantage at high temperature. This Wright's distribution is computed from Eq. 9.3.4 in (Crow and

653 Kimura, 1970) with $N_{e}=N . y$-axis: frequency, $x$-axis: probability density (rescaled for readability on

654 panel A by the inverse of the density at mean frequency). Overall, the figure shows that even in the

655 most favorable conditions, adaptation caused by a recessive beneficial allele cannot be detected within

656 the short 54 or 100 generations of our study. These are the most favorable conditions, as we consider

657 (1) incompletely recessive beneficial alleles, with $h=0.13$ corresponding to the point estimate based

658 on observed survival in our experiment 1 for $\mathrm{VCH}_{08}$ which is certainly a maximum given that the

659 point estimate in $\mathrm{VCH}_{97}$ would be $h=0$ at most); (2) a very strong beneficial effect $s=0.3$, comparable

660 to the highest published field estimates of fitness effects in situations of intense selection pressures

661 (e.g. insecticide resistance (Lenormand et al., 1999)); (3) plausible population sizes of Artemia

662 populations, as census sizes in the field far exceed $10^{6}$ in Vinh Chau saltern; (4) a modest deleterious

663 fitness effect of these beneficial alleles at cold temperature and standard mutation rate $\left(10^{-7}\right.$; a ten-

664 fold larger mutation rate would not alter the conclusion, so that these mutations are unlikely to

665 segregate at a higher frequency than $10^{-3}$ in the population of introduction). In addition, with such

666 intense selection, beneficial alleles spread extremely fast when they reach a frequency above 0.2 (they

667 then reach a frequency of 0.8 in $\sim 20$ generations), so that in this scenario, with a strongly beneficial

668 allele we would be likely to observe a fitness change only between 1984 and 1997 or 1997 and 2008,

669 but not both. 